\title{
EL SANTO SEPULCRO: \\ IMAGEN Y FUNCIONALIDAD ESPACIAL EN LA CAPILLA DE LA IGLESIA DE SAN JUSTO (SEGOVIA)
}

\author{
EDUARDO CARRERO SANTAMARÍA \\ Universidad Autónoma de Madrid
}

La iglesia de San Justo de Segovia se halla extramuros de la ciudad, en el promontorio denominado El Cerrillo, y su existencia consta documentalmente desde comienzos del siglo XII ${ }^{\prime}$. Aunque en época moderna se le añadieron capillas a ambos lados de la nave central ${ }^{2}$, en origen se trató de una iglesia de una sola nave, tal vez con pórticos laterales y rematada en un ábside decorado por un importante ciclo de pintura mural románica, del cual no se tuvo noticia hasta la restauración acometida en la década de los sesenta del presente siglo (Fig. 1). En el muro norte, a la altura del arco triunfal, se encuentra la torre del templo, producto de tres etapas constructivas. Su piso bajo es un espacio cuadrangular cubierto con bóveda de crucería y con dos finalidades funcionales. En primer lugar, en el ángulo sureste, se encuentra la caja de escalera que conduce a los pisos altos de la torre. Por

'En 1120 la documentación catedralicia cita a Pascual, presbítero de San Justo, confirmando un testamento (L.M. Villar García, Documentación medieval de la Catedral de Segovia (1115-1300), Salamanca, 1990, doc. 6, pp. 49-50).

${ }^{2}$ Sobre la fundación de estas capillas, vid. M. GonzÁlez Herrero, El Cristo de los Gascones o Cristo de Segovia, Segovia, 1986, pp. 27-28.

"Anuario de Estudios Medievales". 27 (1997) 

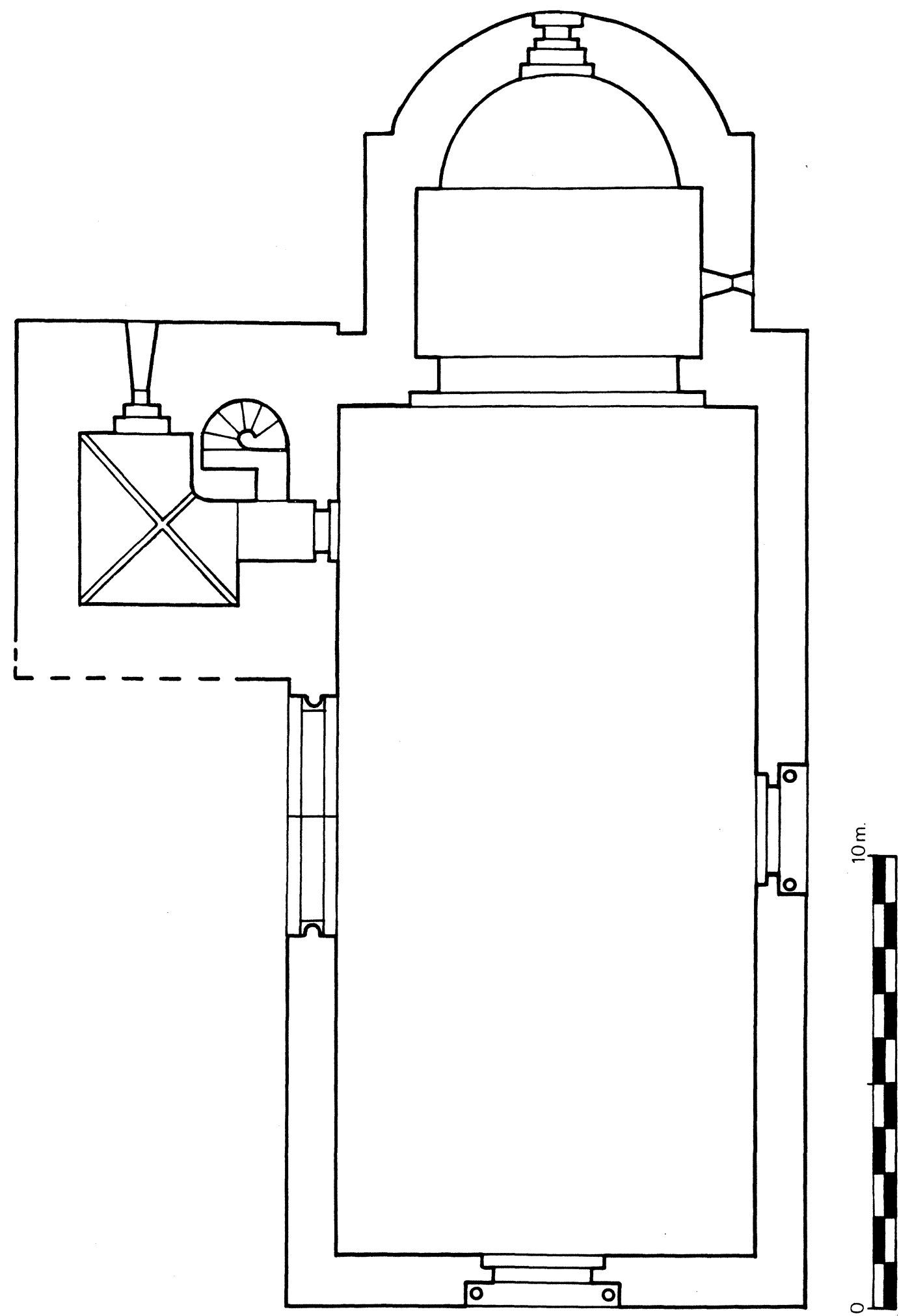

Fig. 1. Esquema de la planta de la iglesia de San Justo (Segovia). 


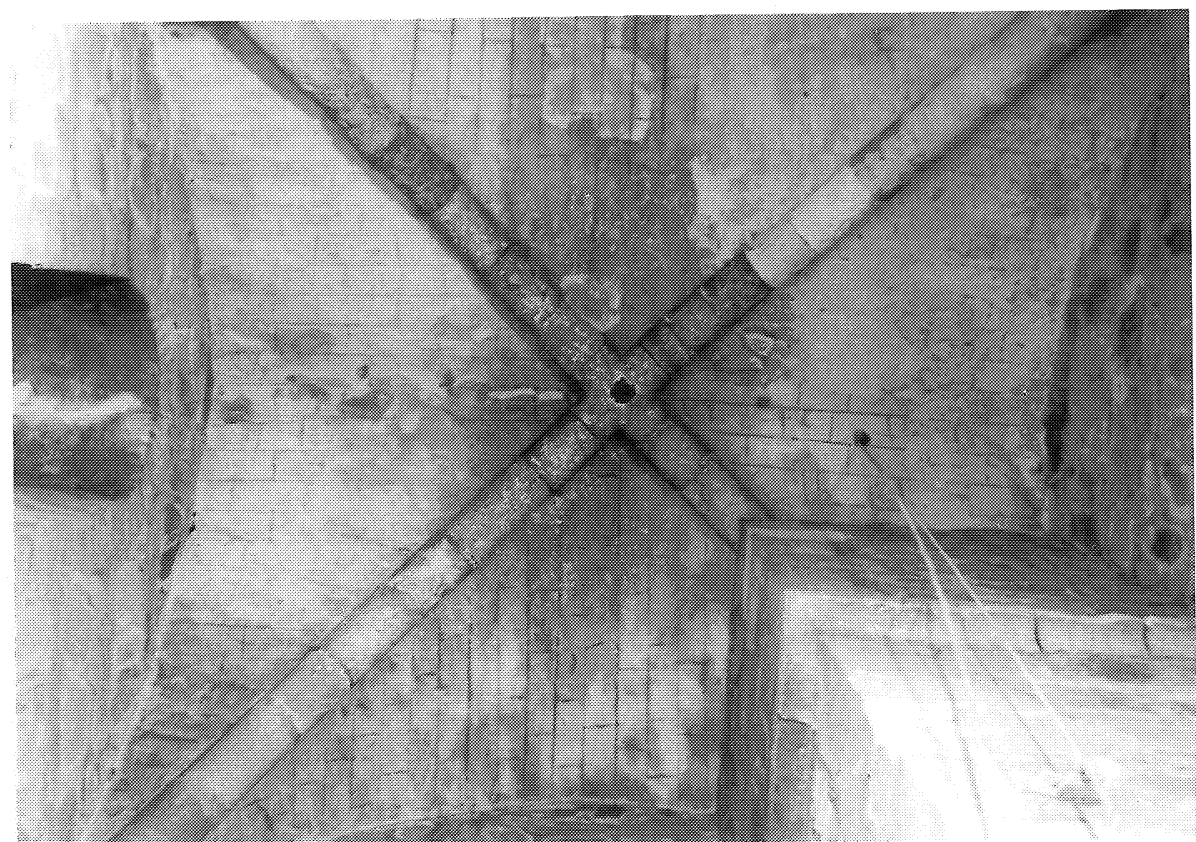

Fig. 2. Bóveda de la Capilla del Santo Sepulcro, San Justo de Segovia.

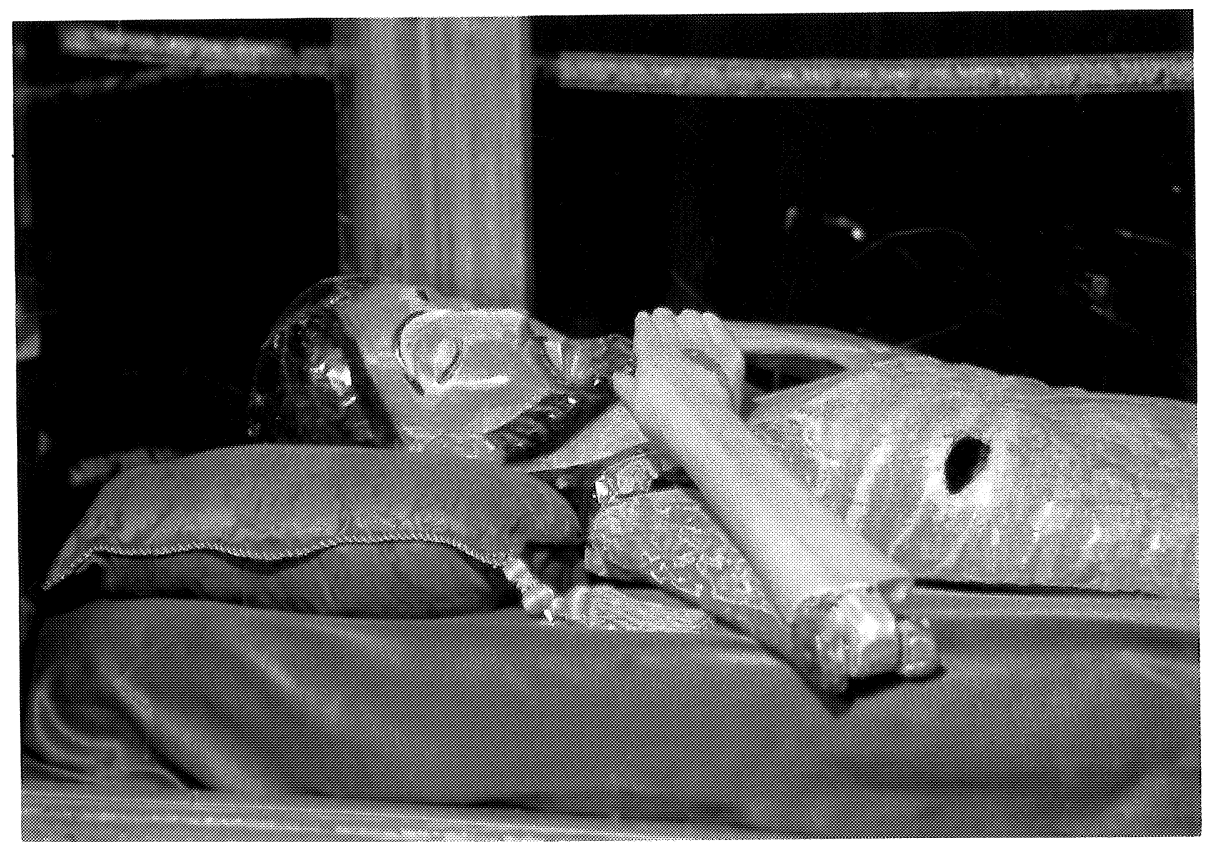

Fig. 3. Cristo de los Gascones, San Justo de Segovia (Foto, D. Rico Camps). 


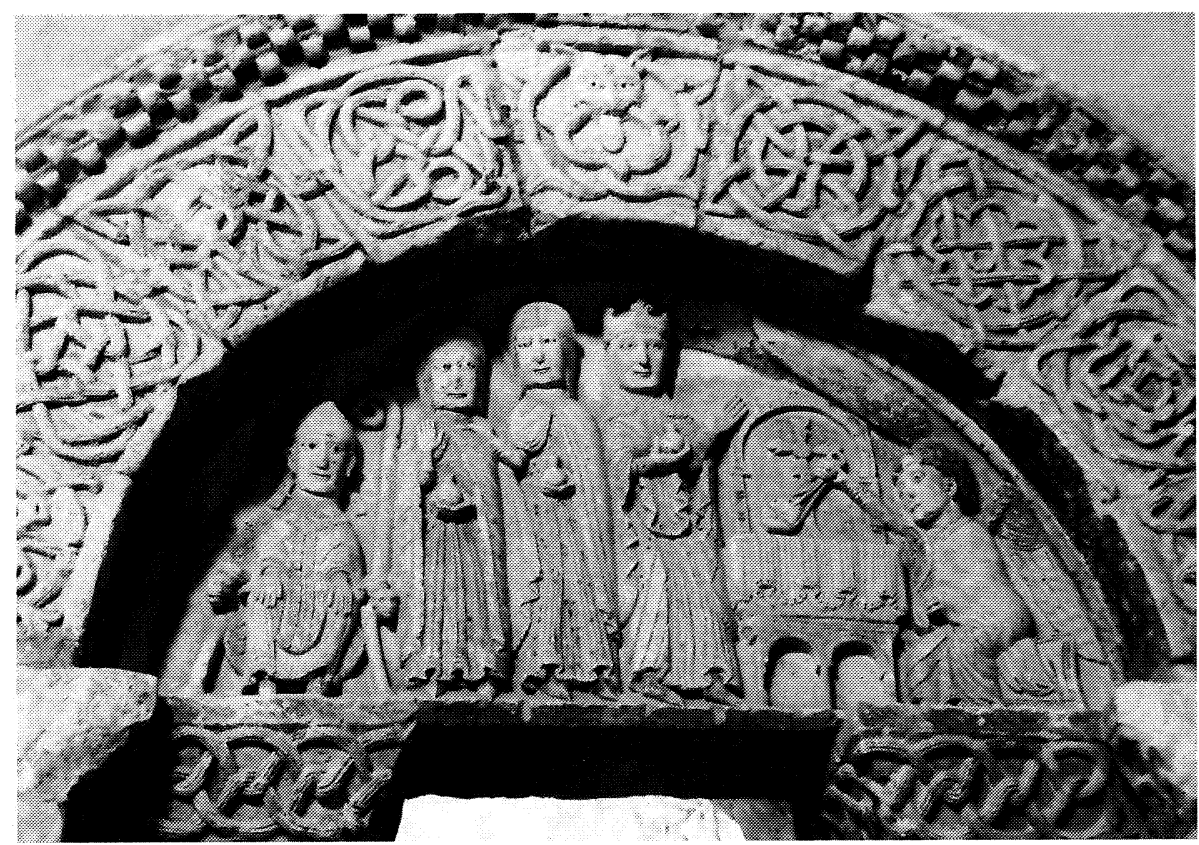

Fig. 4. Tímpano de la puerta de acceso a la Capilla del Santo Sepulcro en San Justo de Segovia

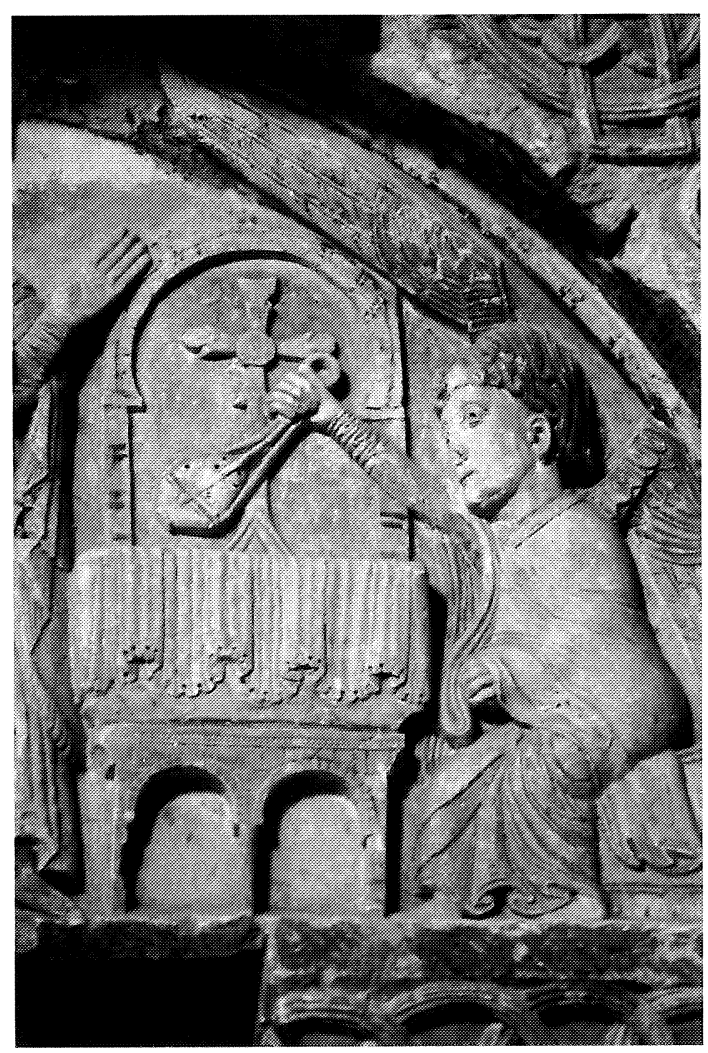

Fig. 5. Detalle del altar del Santo

Sepulcro, con el relicario de la cruz (Foto, D. Rico Camps). 


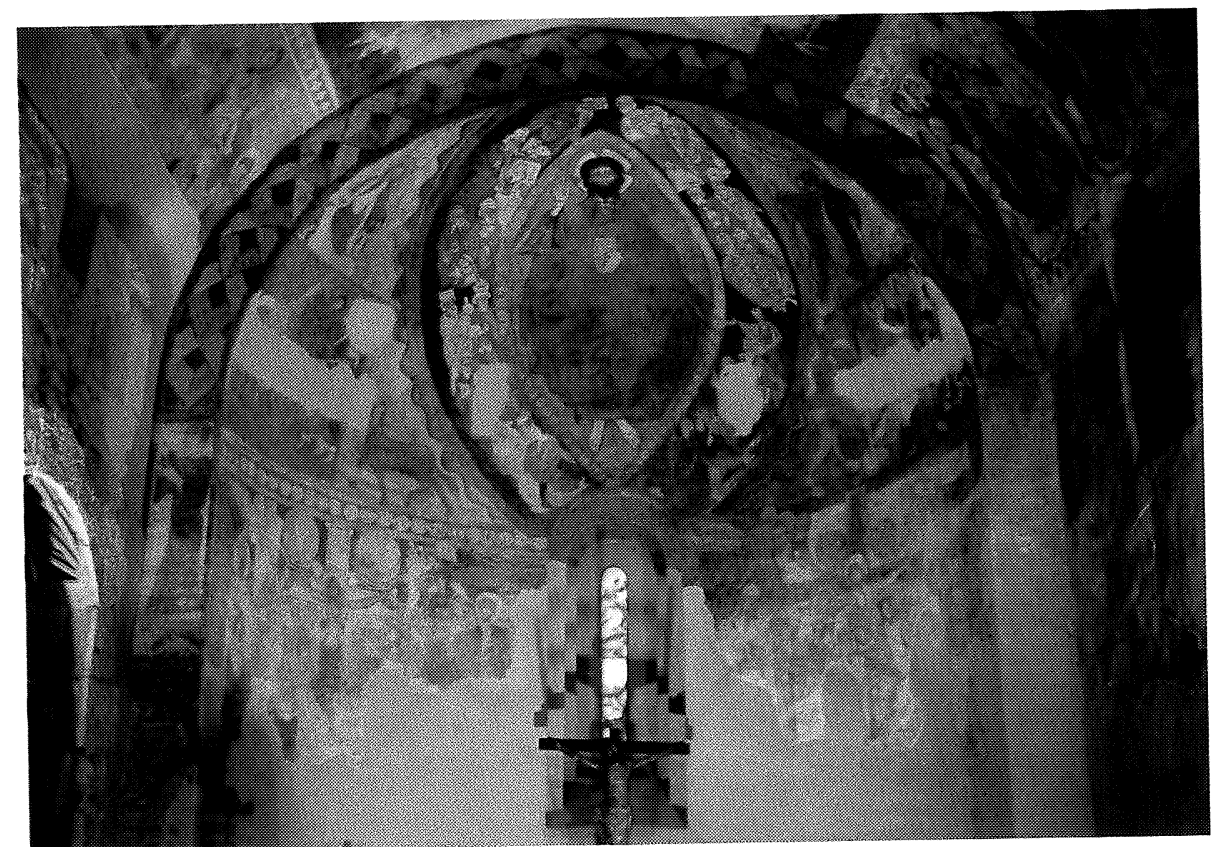

Fig. 6. Ábside de San Justo. Escenas de la Crucifixión y el Descendimiento en el cilindro absidal (Foto, D. Rico Camps). 


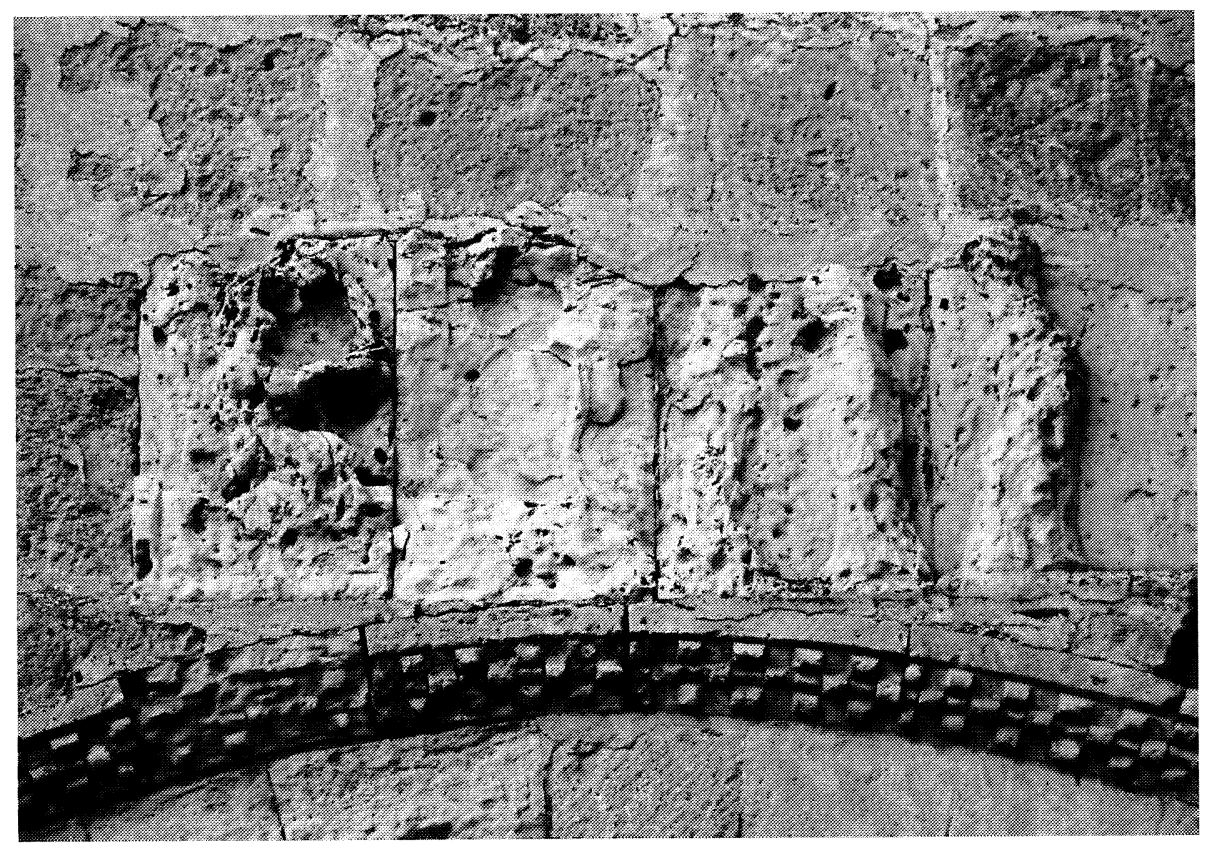

Fig. 7. Relieve sobre la puerta sur de la Vera Cruz (Segovia) (Foto, D. Rico Camps). 
otra parte, el resto de piso bajo, albergó una capilla con advocación al Santo Sepulcro.

La existencia de esta capilla fue coetánea en su uso a la funcionalidad como torre, según se deduce de los citados cambios en la fábrica del campanario, que atestiguan tres fases constructivas diferentes. La primera de éstas llegó hasta el nivel de techumbre de la iglesia. Posterior a esta etapa fue la inclusión dentro del espacio de la capilla de una estructura de fábrica cuadrangular, que aloja en su interior el husillo de la torre. A la vez que se construyó el caracol, la capilla fue cubierta con bóveda de crucería, uno de cuyos nervios apoya directamente sobre la esquina de la caja de escalera ${ }^{3}$. Precisamente, el husillo desemboca en el trasdós de esta bóveda. La diferenciación de espacios entre la caja de la escalera y el resto de la capilla revela el claro propósito de crear una doble funcionalidad en el ámbito interior de la torre (Fig. 2).

En la iglesia, se venera una inusual talla de madera conocida como el Cristo de los Gascones (Fig. 3). Tradicionalmente, se ha admitido que la imagen fue llevada a Segovia por los repobladores de la ciudad procedentes de Gascuña y Alemania, a mediados del siglo $\mathrm{XII}^{4}$. Estilísticamente cercano al Crucifijo de Oña (Burgos), la singularidad del Cristo segoviano estriba en ser un tipo de imagen yacente de características románicas y, por lo tanto, cronológicamente temprana en relación a la posterior popularización de esta representación cristológica ${ }^{5}$. Tiene los ojos cerrados y está articulado de

${ }^{3}$ Este nervio presenta un perfil seccionado en ángulo, destinado desde su concepción a descargar en una esquina. La última etapa constructiva de la torre corresponde al cuerpo de campanas, articulado mediante dos series de arcos moldurados, dentro de la tradición edificatoria local. La arquitectura románica segoviana, muy popular y desarrollada en un amplio marco cronológico, aún requiere un necesario estudio de su génesis y evolución.

${ }^{4}$ L. Calvete, Historia de la vida del glorioso San Frutos Patrón de la ciudad de Segovia, Valladolid, 1610, pp. 255-257; J. de VERA, Piedras de Segovia. Itinerario heráldico y epigráfico de la ciudad, "Estudios Segovianos", n 56, 1950, pp. 261-628, especialmente pp. $579-580$ y 625-626, n. 382; MARQUÉS DE LOZOYA, Las pinturas románicas de la iglesia de San Justo de Segovia, Madrid, 1966, pp. 11-12.

${ }^{5}$ Durante el final de la Edad Media proliferaron tallas de tamaño natural representando las escenas del Llanto sobre Cristo muerto, su variante de la Piedad y, sobre todo, el Santo Entierro. Se trata de grupos escultóricos que, ubicados en una capilla del espacio eclesial a imitación del lugar del Sepulcro, concentraban a su alrededor actos religiosos los días de Viernes Santo y Domingo de Resurrección. La historiografía sobre el tema ha buscado su origen en Alemania (W.H. FORSYTH, The Entombment of Christ. French Sculptures of the Fifteenth and Sixteenth Centuries, Cambridge (Massachusetts), 1970, pág. 22; G. SCHILLER, Iconography of Christian Art, 2 vols., London, 1972, vol. 2, The Passion of Jesus Christ, pág. 180), sin embargo, varios ejemplos peninsulares cronológicamente tempranos han revelado la anticipación de los mismos frente a los arquetipos del Norte de Europa (Cf. J. BRACONS, Els grups del Sant 
hombros y codos, evidenciando su participación en una liturgia de Semana Santa. El Cristo de los Gascones debió jugar un papel primordial en la representación parateatral de la Pasión, ceremonia que podemos suponer integrada por la Crucifixión - como revelan las perforaciones de los pies-, el Descendimiento, la Lamentación, el Santo Entierro y la Visitatio Sepulchri ${ }^{6}$.

A la importancia cronológica del Cristo de los Gascones, hay que añadir la correspondencia entre la talla y la topografía de la iglesia de San Justo. El tímpano de la puerta de acceso a la citada capilla bajo la torre ha suscitado interés por tratarse de un ejemplo atípico de escultura monumental en el interior de una iglesia y por haber conservado la policromía original, al permanecer cubierto por yesos hasta el presente siglo ${ }^{7}$. Aquí se representa una escena en la que, frente a un altar con un ángel turiferario, se disponen de derecha a izquierda tres personajes femeninos portando pomos de esencias $\mathrm{y}$, en el extremo, un hombre ataviado como obispo sentado en la cátedra episcopal (Fig. 4). El significado de la escena ha determinado opiniones diversas. Mientras el Marqués de Lozoya teorizó sobre la posible representación del hallazgo de los restos de los santos mártires Justo y Pastor ${ }^{8}$ -opinión secundada por otros autores ${ }^{9}-$, J. M. Santamaría lo identificó con la visita de las Marías al Sepulcro ${ }^{10}$. M. González Herrero, en su historia del culto al Cristo de los Gascones, juzgó que el evento representado era la inventio de los restos de la Cruz de Cristo por Santa Elena ${ }^{11}$. Esta última afirmación se ve corroborada por el hecho de que la mujer más cercana al

Sepulcre a Catalunya. Precisions sobre l'origen d'aquest model iconogràfic, "Vè Congrés Espanyol d'Historia de l'Art. Barcelona, 29 d'octubre al 3 de novembre de 1984", Barcelona, 1986, pp. 137-145).

${ }^{6}$ Los primeros testimonios de representaciones teatrales del drama de la Pasión se han documentado en las Islas Británicas en el siglo X, puestas en escena por clérigos (R. DoNOVAN, The liturgical drama in Medieval Spain, Toronto, 1985, p. 12).

${ }^{7}$ I.G. BANGo ToRviso, Alta Edad Media. De la tradición hispanogoda al románico, Madrid, 1989 , p. 162. Casi todas las figuras también preservan la pupila de los ojos rellena de pasta negra. Desgraciadamente, una reciente filtración de agua ha deslucido parte de la policromía.

${ }^{8}$ MARQués de Lozoya, Pinturas románicas en la parroquia de San Justo de Segovia, “Archivo Español de Arte”, n 149-152, 1965, pp. 81-85 y Las pinturas románicas..., cit., p. 8. 154.

${ }^{9}$ L.A. Grau LoBo, La Pintura Románica en Castilla y León, Valladolid, 1996, pp. 153-

${ }^{10}$ J.M. Santamaría, Segovia románica, Segovia, 1988, pp. 124-125.

"M. González Herrero, El Cristo de los Gascones, cit., p. 27. 
altar esté coronada como Emperatriz ${ }^{12}$, por el altar que sustenta la Cruz y por la aparición de la efigie de un prelado, según M. González, representando a Macario obispo de Jerusalén.

En mi opinión, a pesar de lo acertado del último análisis interpretativo del tímpano, la escena -indiscutiblemente relacionada con el ciclo hagiográfico de la inventio de la Cruz de Cristo- presenta una serie de interesantes particularidades en cuanto a la tradición hagiográfica hispana en la que se inspiró y, a nivel representativo, elementos que delatan cierta singularidad en la creación y asimilación de motivos iconográficos.

En busca de la Cruz, la emperatriz Elena, madre de Constantino, llegó a Jerusalén donde tuvo que tratar con un judío de nombre Judas que, tras muchas vacilaciones, terminó mostrándole el lugar del Calvario, convirtiéndose después al cristianismo y llegando a la dignidad episcopal de Jerusalén con el nombre de $\mathrm{Ciriaco}^{13}$. Tras la excavación del punto indicado, ocupado hasta el momento por un templo romano con culto a Venus-Afrodita ${ }^{14}$, Santa Elena encontró las tres cruces de Cristo y los dos ladrones. Para determinar en cuál de éstas se crucificó a Jesús, las mostró al entonces obispo hierosolimitano Macario quien, a su vez, hizo llevarlas a una mujer enferma que sanó al contacto de la Cruz verdadera ${ }^{15}$.

\footnotetext{
${ }^{12}$ Las representaciones iconográficas y textos concernientes a Elena la presentan coronada y con manto real desde la Tardoantigüedad [Cfr. A. AMORE y E. CROCE, Elena, en "Bibliotheca Sanctorum", 13 vols., Roma, 1961-1970, vol. IV, Roma, 1964, reed. 1987, col. 993; M. MARCOS, Representaciones visuales del poder en época tardoantigua: La imagen de la emperatriz cristiana, "Hispania Sacra", 48 (1996), pp. 513-540]. Por el contrario, en SaintPaul de Dax existe una imagen escultórica de la Visita al Sepulcro por las Santas Mujeres en la que las tres aparecen coronadas (E. MÂLE, L'art religieux du XIIe siècle en France. Étude sur les origines de l'iconographie du Moyen Age, Paris, 1905, $7^{\mathrm{a}}$ ed. Paris, 1966, p. 129).

${ }^{13}$ Santiago De La Vorágine, La leyenda dorada, 2 vols., Madrid, 1982, vol. I, pp. $287-$ 294. Para fuentes más precisas sobre la historia de Elena, vid. A. FROLOw, La relique de la Vraie Croix. Recherches sur le développement d'un culte, Paris, 1961; M. VAN ESBROECK, Jean II de Jérusalem et les cultes de Saint-Étienne, de la Sainte-Sion et de la Croix, "Analecta Bollandiana”, 102 (1984), pp. 99-134, especialmente pp. 126-134; J.-M. CALLU, Le Roman de Constantin et d'Hélène (XIe-XIIe siècles), "Bulletin de la Société Nationale des Antiquaires de France" (1990), pp. 21-22; S. BORGEHAMMAR, How the Holy Cross was found: from Event to Medieval Legend, Stockholm. 1991: J.W. DRIJVERS, Helena Augusta. The Mother of Constantine the Great and the Legend of Her Finding of the True Cross, Leiden, 1992; F.A Consolino, L'invenzione di una biografia: Almanno di Hautvillers e la vita di sant'Elena. "Hagiographica", I, (1994), pp. 81-100.

${ }^{14}$ Este templo fue mandado construir por el emperador romano Adriano, tras su reconstrucción de la ciudad en el siglo II d. C.

${ }^{15} \mathrm{La}$ cenefa inferior del tapiz de la Creación de la catedral de Girona tiene una amplia representación de la historia de Santa Elena y la Cruz, con un destacado papel de Judas (Vid. P. DE PALOL, El Tapís de la Creació de la Catedral de Girona, Barcelona, 1986, pp. 127-133).
} 
La historia de Elena propició la aparición de un ciclo iconográfico propio. Existen numerosos ejemplos miniados de la historia de la Cruz, que representan a la Emperatriz en tratos con el judío Judas y la excavación del Calvario por éste último ${ }^{16}$. En la plástica bizantina es habitual su aparición en monedas y mosaicos junto a Constantino y sosteniendo la Cruz, ejemplo seguido en las pinturas murales de Santa María de Barberà (Barcelona). Durante la Baja Edad Media, suele ser representada acompañando al obispo Macario en el momento de la verificación de la cruz verdadera ${ }^{17}$. A esto hay que aducir que el ejemplo de San Justo de Segovia no se atiene al relato del momento de la inventio narrado en las Leyendas hagiográficas citadas hasta el momento. Esta es la razón por la cual la comprensión iconográfica de este tímpano resulta problemática, siendo la Inventionis sanctae Crucis incluida en un texto peninsular -el Pasionario Hispánico- la que en mi opinión permite una correcta interpretación de la escena representada ${ }^{18}$.

Como puso de manifiesto A. Fábrega Grau, la enraizada devoción a la Cruz en la Península Ibérica desde la Alta Edad Media sólo fue equiparable al culto profesado a la misma en el Oriente cristiano ${ }^{19}$. Datada desde el siglo VII, la festividad de la Invención de la Santa Cruz era celebrada el día 3 de mayo, aunque su inclusión como parte de la liturgia hispana parece que no se produjo hasta comienzos del siglo $\mathrm{X}^{20}$. Con respecto al resto de las mencionadas historias de la inventio, la contenida en el Pasionario Hispánico ofrece algunas divergencias centradas, en lo que a la iconografía del tímpano de San Justo se refiere, en la participación del judío Judas y en la actividad de la emperatriz Elena tras el hallazgo. Ya he señalado la singularidad de la presencia de un obispo y un altar con una Cruz en la escena esculpida para la capilla de San Justo de Segovia,

\footnotetext{
${ }^{16}$ Cfr. P. DE Palol, El Tapís de la Creació, cit.; ID., El bordado del Génesis de la Catedral de Gerona, "Goya", 9 (1955), pp. 168-176; ID., Une broderie catalane d'époque romane: La Genèse de Gérone, "Cahiers Archéologiques", XI (1957), pp. 219-251, especialmente, pp. 237-246.

${ }^{17} \mathrm{G}$.W. BENSON, The Cross. Its History and Symbolism, New York, 1934, $2^{\mathrm{a}}$ edic. New York, 1983, pp. 31-35; L. RÉAU, Iconographie de l'Art Chrétien, III, Iconographie des Saints, 2, París, 1958, pp. 633-636; A. AMORE y E. CROCE, Elena, op. cit., cols. 988-995; H.W. VAN Os y G. JÁSZAI, Kreuzlegende, en E. KIRSChBAUM (dir.), "Lexicon der Christlichen Ikonographie”, 8 vols., Fribourg, 1970, reed. 1990, vol. 2, 642-649.

${ }^{18}$ A. Fábrega Grau, Pasionario Hispánico, 2 vols., Madrid-Barcelona, 1953-1955, II, Texto, Madrid-Barcelona, 1955, pp. 260-266.

${ }^{19}$ A. Fábrega Grau, Pasionario, cit., I, Estudio, Madrid-Barcelona, 1953, pp. 208-210.

${ }^{20}$ A. FÁbrega Grau, Pasionario, cit., I, pp. 208-209.
} 
elementos que van a ser determinantes para la comprensión del motivo representado. En las restantes historias de la Invención de la Santa Cruz, Macario no asistió a Elena en su búsqueda, actuando simplemente como intermediario que verificaba la Cruz verdadera al sanar a un enfermo con el contacto de ésta. En el Pasionario Hispánico Macario obispo de Jerusalén ni siquiera aparece, siendo su papel ocupado por el judío Judas, cuya participación en la narración es mucho más destacada que en el resto de los textos hagiográficos, estando íntimamente ligado a todo el desarrollo de la historia. Éste, tras realizar el hallazgo de las tres cruces a instancias de Elena, dirimió cuál era la Cruz de Cristo al colocarla sobre un cadáver que resucitó a su contacto:

Interrogabat autem eum beata Helena, qualis esset crux Christi, dicens: Scimus enim quia cetere cruces latronum due sunt, qui cum eo crucifixi sunt. Et ponentes eas in media civitate, expectabant gloriam Christi. Et circa horam nonam ferebatur mortuus iuvenis in grabato: Iudas autem gaudio repletus, dixit: Nuc cognoscis, domina, dilectissimum lignum et virtutem eius. Et teneri Iudas grabatum fecit, et deponi mortuum, et posuit super eum singulas cruces, et non surrexit; inposuit autem tertiam crucem dominicam super mortuum, et statim surrexit qui mortuus fuerat iuvenis, et omnes qui aderant florificabant Dominum ${ }^{21}$.

Como colofón a su ayuda a Elena, Judas fue bautizado y, ante su conversión, la misma Emperatriz se encargó de solicitar al Papa Eusebio la ordenación de Judas como obispo de Jerusalén con el nombre de Ciriaco:

Iudas autem accepit babtismum incorruptionis in Christo Iesu, et precedentibus signis, quum moraretur adhuc beata Helena in Ierosolymam ostensus est fidelis et comendavit eum episcopo, qui illo tempore erat, qui et babtizavit eum in Christo Iesu. Factum est autem beatum episcopum dormitionem accipere in Christo Iesu. Beata autem Helena accersivit Eusebium episcopum urbis Rome, et ordinavit Iudam episcopum Ierosolyme ecclesie Christi, et mutavit nomen eius, et vocatus est Quiriacus ${ }^{22}$

\footnotetext{
${ }^{21}$ A. Fábrega Grau, Pasionario, cit., II, p. 264.

${ }^{22}$ A. FÁbrega Grau, Pasionario, cit., II, p. 265. La figura de Ciriaco o San Judas ha sido asociada a Giuda, último obispo judeo-cristiano de Jerusalén del siglo II, sufriendo martirio con Juliano el Apóstata. Otra tradición lo sitúa emigrado a Italia donde llegó a ser obispo de Ancona, ciudad de la que es patrón y donde es venerado desde la Alta Edad Media [Vid. B. DE GAIFFIER, 'Sub Juliano Apostata' dans le martyrologe romain, "Analecta Bollandiana", LXXIV (1956), pp. 5-49, especialmente p. 39; M. NATALUCCI, Ciriaco, vescovo di Gerusalemme, en "Bibliotheca Sanctorum", 13 vols., Roma, 1961-1970, III, reed. Roma, 1990,
} 
La segunda diferencia, respecto a otras narraciones, es el relato de la confección por mandato de Elena de un recipiente adecuado para albergar los restos de la Cruz. Después del milagroso reconocimiento del lignum crucis, la emperatriz ordenó protegerlo en un relicario elaborado con oro y piedras preciosas, construyéndose después la basílica del Santo Sepulcro:

Quum magno autem studio exornans pretiosam crucem, auro et lapidibus pretiosis, faciens loculum argenteum, in ipsio colocavit crucem Christi; et eclesiam construxit in ipso Calvarie locum ${ }^{23}$.

Sabemos que Constantino, hijo de la emperatriz, favoreció la edificación del templo con la rotonda de la Anástasis circundando el sepulcro, sobre el que se colocó un baldaquino ${ }^{24}$. Como señaló $\mathrm{K}$. J. Conant, siguiendo el precursor estudio del maestro André Grabar sobre los martyria $^{25}$, la importancia arquitectónica del Santo Sepulcro se dejó sentir en sus representaciones iconográficas, que tomaron la forma de un edificio centralizado cubierto con un cimborrio ${ }^{26}$. La escena que más aquejó esta inclusión de la arquitectura del momento en las representaciones de la historia testamentaria fue el motivo de la Visita de las mujeres al Sepulcro. Desde la Tardoantigüedad y la Alta Edad Media, la llegada de las Marías se vio acompañada de una imagen del Sepulcro directamente influenciada por el edificio constantiniano ${ }^{27}$. Creo evidente que en el ejemplo segoviano nos

cols. 1296-1297]. El culto a San Judas obispo apareció en la Península durante el sigio XI. como refleja el Pasionario de Santo Domingo de Silos conservado en la Biblioteca Nacional de París (A. FÁBrega Grau, Pasionario, cit., I, pp. 209-210 y 232-235).

${ }^{23}$ A. FÁBrega GraU, Pasionario, cit., II, pp. 264-265.

${ }^{24} \mathrm{~K} . J$. CONANT, The original buildings at the Holy Sepulchre in Jerusalem, "Speculum", XXXI-1 (1956), pp. 1-48.

${ }^{25} \mathrm{~A}$. GRABAR, Martyrium. Récherches sur le culte des reliques et l'art chrétien antique, 3 vols., Paris, 1946-1948.

${ }^{26} \mathrm{~K} . J$. CONANT, The original buildings, cit., pp. 3-5. También, R.G. OSTERHOUT, The Temple, the Sepulchre and the Martyrion of the Savior, "Gesta", XXIX/1 (1990), pp. 44-53.

${ }^{27}$ Vid. F. HEBER-SUFFrIN, Copie et creation dans l'enluminure carolingienne. L'exemple de l'architecture, "Les Cahiers de Saint-Michel de Cuxa", 22 (1991), pp. 57-77. Por el contrario, para C. HEITZ [Sepulcrum Domini: le Sépulcre visité par les Saintes Femmes (IX'-XI siècle), en Sot, M. (coord.), "Haut Moyen-Age. Culture, éducation et société. Études offertes à Pierre Riché" coord. M. Sot, Paris, 1990, pp. 389-400 y Architecture et liturgie: Le SaintSepulcre et l'Occident, "Les Cahiers de Saint-Michel de Cuxa", 22 (1991), pp. 43-56], en las representaciones del Sepulcro de Cristo dentro del ámbito carolingio se sustituyó la figuración de la Anástasis de Jerusalén por imágenes de los macizos occidentales de la arquitectura de la 
hallamos ante una contaminación entre ambas escenas, es decir, la visita de las Marías al sepulcro y el hallazgo de la Cruz por la Emperatriz Elena y, tras el testimonio del Pasionario Hispánico, parece evidente que la cruz colocada sobre el altar del tímpano de San Justo obedece al expreso deseo de representar el relicario realizado a instancias de la emperatriz ${ }^{28}$.

El lado derecho del tímpano muestra al ángel del relato de la visita de las Marías $^{29}$, que inciensa el altar sobre la tumba de Cristo (Fig. 5). Esta disposición de altar ha sido considerada por J. E. Íñiguez como la representación de un ara portátil con un baldaquino que podía hacer las funciones de pequeño retablo ${ }^{30}$. Dejando a un lado la cuestión de su condición o no como elemento portátil, pienso que el altar del tímpano de San Justo figura el existente en el Santo Sepulcro de Jerusalén y, por ende, en ningún momento puede ser considerado como una representación de la yacija del sepulcro de Cristo ${ }^{31}$. Matizando su auténtica identidad, este altar sustenta el identificado relicario realizado por Elena y está cubierto con el baldaquino que, según Conant, en el Santo Sepulcro de Jerusalén funcionaba como un iconostasio sin imágenes ${ }^{32}$. Como en el caso de la Visita de las Santas Mujeres, las tres damas de San Justo se sitúan frente al altar llevando pomos de esencias en ofrenda. La primera de ellas es Elena coronada, seguida de las dos damas de su corte. Por fin, en el extremo izquierdo, se halla Ciriaco

época, en los cuales se celebraban ceremonias litúrgicas de la Pasión.

${ }^{28}$ Considero demasiado arriesgado suponer que la escena del tímpano de San Justo sea la representación escultórica de un oficio litúrgico de la Visita de las Marías al Sepulcro -en este caso ante un obispo-, como atribuye C. Heitz al marfil de la Staatsbibliothek de Munich (C. HEITZ, Sepulcrum Domini: le sépulcre, cit., p. 392 y Architecture et liturgie, cit., p. 45). E. MÁle (L'art religieux du XII' siècle en France, cit., pp. 125-139) defendió la influencia del teatro litúrgico en la iconografía de la Visita al Sepulcro, posibilidad hoy puesta en duda (vid. al respecto Y. ESQUIEU, Théâtre liturgique et iconographie: l'exemple des Saintes Fermmes au tombeau dans la France méridionale et l'Espagne du Nord, "Cahiers de Fanjeaux", 28, Le décor des églises en France méridionale (XIII'-mi XV' s.), Fanjeaux, 1993, pp. 215-231).

${ }^{29}$ Mateo, 28, 5.

${ }^{30}$ J.E. ÍṄigueZ, El altar cristiano, II, De Carlomagno al siglo XIII, Pamplona, 1991, pp. 237 y 240

${ }^{31}$ En relación a esto, existen algunas imágenes de la Visita de las mujeres, en las que el sepulcro aparece representado como un altar cubierto por un baldaquino, aquejando de este modo la influencia de la imagen arquitectónica del Santo Sepulcro de Jerusalén. Asi ocurre en el Panel del Sancta Sanctorum (c.600) del Vaticano, en el Sacramentario de Drogon (f. 91) o en algunos objetos vinculados a la peregrinación a Tierra Santa (Vid. K.J. CONANT, The original buildings, cit., p. 43; F. HEBER-SUFFRIN, Copie et creation, cit., p. 73; R.G. OSTERHOUT, The Temple, the Sepulchre, cit., p. 48).

${ }^{32}$ K.J. CONANT, The original buildings, op. cit., p. 4. 
como obispo hierosolimitano. Como ya he puntualizado, a diferencia de Macario, este prelado intervino en el momento del hallazgo y en la identificación de la Cruz verdadera y, por lo tanto, en la representación que tratamos su imagen fue utilizada lógicamente como figura aclaratoria ante el posible desconcierto que pudiera derivar de la representación de las tres mujeres. Tras el hallazgo y la construcción de la iglesia, Ciriaco fue al lugar del Calvario a orar:

Sanctus vero episcopus Quiriacus, veniens ad Calvarie locum una cum multis fratibus, qui in Domino Iesu Christo crediderant per inventionem sancte crucis, et quod in mortuo factum est signum, et elevans in celum oculos et manibus, simulque percutiens pectus ${ }^{33}$.

En fecha posterior -1208-, la iglesia de la Vera Cruz de Segovia en origen bajo la advocación del Santo Sepulcro recibió una representación escultórica similar. Sobre su puerta meridional se ubicó un relieve rectangular que en esta ocasión sí parece representar la llegada de las Marías al Sepulcro (Fig. 7). La placa tardorrománica de la Vera Cruz presenta dudas insoslayables debidas a la aparición de un quinto personaje entre las Marías y el ángel, irreconocible por el lamentable estado de conservación del relieve, pero que bien pudiera tratarse del segundo ángel que ocupaba la cabecera del sepulcro en el Evangelio de Juan (Jn 20, 11-13) ${ }^{34}$.

Ciertamente, en San Justo se quiso representar la adoración por Santa Elena de los restos de la Cruz colocados en la nueva basílica del Santo Sepulcro $^{35}$. Con toda probabilidad, el maestro que esculpió el tímpano de la capilla fue aleccionado sobre la escena a representar mas, careciendo de un modelo a todas luces inusual en la escultura románica castellana, debió tomar como patrón iconográfico la Visita de las Marías al Sepulcro, introduciendo algunas variantes con el fin de evitar la confusión. Estos fueron, en primer lugar, la alegoría de la Anástasis representada mediante un altar con una cruz relicario y cubierto por un baldaquino, junto al que no

\footnotetext{
${ }^{33}$ A. FÁBrega Grau, Pasionario, cit., II, p. 265.

${ }^{34}$ Un factor más a tener en cuenta en la relación entre ambas iglesias segovianas es el tipo de bóvedas empleadas en la cubrición de la capilla de San Justo y del edículo de la Vera Cruz. Las afinidades estilísticas entre los sistemas edificatorios de ambos abovedamientos sitúan su realización dentro de un mismo contexto cronológico, esto es, los albores del siglo XIII.

${ }^{35}$ El relato del Pasionario Hispánico concluye con la visita de Ciriaco, Elena y otros hermanos a orar al Calvario (A. FÁBREGA GRAU, Pasionario, cit., II, p. 265).
} 
se incluyeron los habituales soldados dormidos que guardaban el sepulcro en la escena de las Marías (Fig. 5). Por otro lado, la aparición de la primera dama coronada como la emperatriz Elena y, por último, pero jugando un papel determinante en la narración, la comparecencia de Judas-Ciraco sentado en su cátedra episcopal. Elena, considerada como la heredera de la reina de Saba en la historia del lignum crucis y la antítesis de Elena de Troya ${ }^{36}$, es representada en el tímpano segoviano junto a sus damas de corte como nuevas Marías acercándose, esta vez, al Santo Sepulcro de Jerusalén.

La identificación de la escena del tímpano de San Justo va en paralelo con la advocación de la capilla al Santo Sepulcro apoyada, además, en que allí se situaba la figura yacente y articulada del Cristo de los Gascones $^{37}$. Esto pone de manifiesto la temprana aparición en Castilla de capillas dedicadas a albergar una imagen de Jesús muerto, unidas a la representación de ceremonias litúrgicas basadas en la Pasión. A la imagen, capilla y tímpano hay que añadir la temática elegida para el conjunto de pinturas murales del ábside. Mientras en el cascarón de la bóveda se ubicó una maiestas Domini de carácter apocalíptico, en el tramo recto y en el cilindro absidal se realizó un ciclo dedicado a la Pasión de Cristo, poco habitual en esta zona de la iglesia ${ }^{38}$. El tramo recto presenta a izquierda y derecha, respectivamente, la Santa Cena y una detallada escena del Prendimiento, mientras en el cilindro absidal se situaron la Crucifixión y el Descendimiento (Fig. 6).

\footnotetext{
${ }^{36}$ F.E. Consolino, L'invenzione di una biografia, cit., pp. 93-96.

${ }^{37}$ MARQUÉS DE LOZOYA, Las pinturas románicas, p. 12.

${ }^{38}$ En la Península conservamos otros casos en los que el ábside se decoró con escenas de la Pasión. Así ocurre en la iglesia zaragozana de Bagüés (G. BORRÁs Gualís y M. García GuATAS, La pintura románica en Aragón, Zaragoza, 1978, pp. 62-74). En la iglesia de San Juan Bautista de Ruesta (Zaragoza) se conserva una Crucifixión (J. SUREDA, La pintura románica en España, Madrid, 1985, pp. 316-319, cat. n ${ }^{\circ} 8$ ), en Sant Andreu de Baltarga (Lleida) restan fragmentos de una Última Cena y una Crucifixión, en la de Sant Esteve de Marenyà (Girona), el registro inferior del ábside muestra otra Crucifixión y a las Marías ante el sepulcro y en la de Sant Romà de Càldegues se conserva una Crucifixión (J. SUREDA, La pintura románica en Cataluña, Madrid, 1981, pp. 328-329, cat. $\mathrm{n}^{\circ} 69$; p. 296, cat. $\mathrm{n}^{\circ} 25$ y pág. 373 , cat. $\left.n^{\circ} 144\right)$. En estos cuatro casos, las escenas indicadas no son parte de ciclos absidales centrados en la Pasión, sino que aparecen junto a otros momentos de la vida de Cristo o como escenas aisladas. Por otro lado, en el panteón real de San Isidoro de León y en la sala capitular del monasterio de Sijena (Huesca), sí aparecen ciclos pictóricos de la Pasión, aunque aquí están vinculados a un contexto arquitectónico y litúrgico diferente.
} 
La talla del Cristo segoviano debió adquirir connotaciones cuasi relicarias y ser venerado como tal $^{39}$. Esto influenció determinantemente el orden de la topografía eclesial, con la ubicación de una capilla del Santo Sepulcro en la zona inferior de la torre. La influencia de las reliquias en la disposición de iglesias es conocida desde la Alta Edad Media, al igual que la liturgia, factor determinante en la estructuración de los templos y en su decoración ${ }^{40}$. En San Justo de Segovia, es sugestivo el hecho de la confluencia de varios elementos plásticos y arquitectónicos - tímpano, imagen, capilla y ciclo pictórico- invocando un culto muy determinado. A pesar de la cuestionada realidad de un drama religioso castellano anterior al siglo $\mathrm{XV}^{41}$, creo que las pruebas materiales de la parroquia de San Justo conducen a la evidencia, sino de un teatro sacro, al menos de una liturgia compleja vinculada a la Pasión de Cristo. A esto habría que añadir la existencia desde el siglo XI de celebraciones ligadas a las Vísperas del Viernes Santo, como ocurre en el caso del Missale Bracarense y las Visitatio Sepulchri de las catedrales de Vic, la Seu d'Urgell, Girona, Santiago de Compostela y del monasterio de Santo Domingo de Silos ${ }^{42}$.

En el siglo XIII, las Siete partidas del rey Alfonso X proporcionan más información sobre el drama litúrgico. En el conocido texto de la Partida

\footnotetext{
${ }^{39}$ Desconozco si la talla alberga en la espalda una teca eucarística, como ocurre en otros casos.

${ }^{40}$ En relación a la función litúrgica de la pintura mural, vid. E. PALAzzo, Les practiques liturgiques et devotionelles et le decor monumental dans les églises du Moyen Âge, en "L'emplacement et la fonction des images dans la peinture murale du Moyen Age. Actes du 5ème séminaire international d'art mural 16-18 septembre 1992 - Saint-Savin", Saint-Savin-surGartempe, 1992, pp. 45-56. En lo que atañe a la liturgia hispánica, vid. I.G. BANGO TORVISO, San Pelayo de Perazancas. Las imágenes de un calendario románico organizadas según la vieja liturgia hispana, y su contexto en el conjunto del programa iconográfico, "Anales de Historia del Arte", 4 (1993-94), "Homenaje al profesor Dr. D. José M ${ }^{a}$ Azcárate y Ristori", pp. 545558 .

${ }^{41}$ F. LÁzaro CARreter, Teatro medieval, Madrid, 1976, p. 40. Vid. la aclaratoria aportación de los recientes trabajos E. CASTRO CARIDAD, Introducción al teatro latino medieval. Textos y públicos, Santiago de Compostela, 1996 y, en edición de la misma autora, Teatro medival. 1 El drama litúrgico, Barcelona, 1997.

${ }^{42}$ Vid. V. García DE LA CONCha, Dramatizaciones litúrgicas pascuales de Aragón y Castilla en la Edad Media, en "Homenaje a Don José María Lacarra de Miguel", V, Zaragoza, 1977, pp. 153-175; E. CASTRO CARIDAD, El texto y la función litúrgica del "Quem queritis" pascual en la catedral de Vic, "Hispania Sacra", XLI (1989), pp. 399-420; P. ROMANO ROCHA, La liturgia de Compostela a fines del siglo XII, en "Actas Simposio Internacional sobre 'O Portico da Gloria e a arte do seu tempo', Santiago de Compostela, 3-8 de Outubro de 1988", Santiago de Compostela, 1991, pp. 397-410 y, muy especialmente, E. CASTRO CARIDAD (ed.), Teatro medieval. 1 El drama, cit.
} 
I, ley 34, título VI, se referencian las ceremonias poco decorosas realizadas en el interior de las iglesias, remarcando en cambio la conveniencia de celebrar las representaciones de Navidad, Epifanía y, en Semana Santa, la Visita al Sepulcro ${ }^{43}$. Los dramas litúrgicos navideños se componían fundamentalmente por el Officium Pastorum, el Ordo Prophetarum y el Ordo Rachelis. La Epifanía se festejaba con el Ordo Stellae, dedicado a la adoración de los reyes de la tierra personificados en los tres Magos. Por último, en Pascua, el tropo Quem queritis in sepulchri, incluido en el drama de la Visitatio Sepulchrit ${ }^{44}$.

Más puntual, aunque igualmente interesante, es una noticia datada en 1273 sobre las procesiones y celebraciones realizadas por el cabildo de la catedral de Zamora. En ésta se citan los actos litúrgicos del Domingo de Ramos poniendo otra vez de relieve la existencia de representaciones litúrgicas de Cuaresma ${ }^{45}$.

43" ...ca la Eglesia de Dios es fecha para orar, e non para fazer escarnios en ella: ca assi lo dixo nuestro Señor Iesu Christo en el euangelio, que la su casa era llamada casa de oración, e non debe ser fecha cueua de ladrones. Pero representación ay que pueden los clérigos fazer: assí como de la nascencia de Nuestro Señor Iesu Christo, en que muestra como el ángel vino a los pastores, e como les dixo como era Jesu Christo nacido. E otrosí de su aparición, como los tres Reyes magos lo vinieron adorar. E de su resurreción, que muestra que fue crucificado e resuscitó al tercero día: tales cosas como estas, que mueuen al ome a fazer bien, e a aver deuoción en la fe, pueden las fazer e demás por que los omes ayan remembrança, que segund aquellas, fueron las otras fechas de verdad. Mas esto deuen fazer apuestamente, e con gran deuoción: e en las cibdades grandes donde ouieren Arçobispos, o Obispos, e con su mandado dellos, o de los otros que touieran sus veces e non lo deuen fazer en las aldeas, nin en los logares viles, ni por ganar dineros con ellas" (Partida I, título VI, ley XXXIV, Las Siete Partidas del Sabio Rey don Alfonso el Nono, Salamanca, MDLV, reed. facs., 3 vols., Madrid, 1985, vol. I, f. 61r. y v.). Sobre Alfonso X y la escena teatral de su época, vid. H. LóPEZ MORALES, H., Alfonso $X$ y el teatro medieval castellano, "Revista de Filología Española", LXI/3-4 (1991), pp. 227-252.

${ }^{44}$ E. Castro Caridad (ed.), Teatro medieval. 1 El drama, cit., pp. 105-109.

${ }^{45} \mathrm{El}$ documento en cuestión refiere una casa lindante con el castillo de Zamora, junto a la que "suelen cantar los monaziellos en día de Ramos cuando vienen de la procesión". Escasos años después, otro documento sobre la misma casa concedía el permiso al obispo, cabildo y clerecía de la ciudad para que "ay livremente entrada e salida sobre la puerta del castiello de piedras de Mercadiello para cantar los viessos e fazer representamientos de Nuestro Sennor en día de Ramos" (Archivo de la Catedral de Zamora, Tumbo Blanco, ff. 25r.-26r. Cit. en M. SÁnChez Rodríguez, La Diócesis de Zamora en la segunda mitad del siglo XIII, "Primer Congreso de Historia de Zamora", 3 vols., Zamora, 1989-1991, 3, Medieval y Moderna, Zamora, 1991, pp. 147-171 y F. FERRERO FERRERO, La primera procesión de Semana Santa conocida en Zamora, en "Civitas. MC Aniversario de la Ciudad de Zamora”, Zamora, 1993, pág. 181). Comparto la opinión de M. SÁnCHEZ RodrígueZ (Tumbo Blanco de Zamora, Salamanca, 1985, pp. CXXXVII-CXXXVIII; La Diócesis de Zamora, cit. , pág. 158, n. 53) y F. FERRERO FERRERO (La primera procesión, cit.) que resaltan la importancia de estos textos dentro de las noticias sobre representaciones y procesiones litúrgicas medievales. En cambio, J. SÁNCHEZ HERRERo (Las celebraciones del Descendimiento y Santo Entierro en el contexto 
Con referencia a Segovia, si bien de fecha posterior, el sínodo de 1375 resulta esclarecedor. En éste se dictaminaron disposiciones respecto al monumento de Semana Santa y a la representación de la Visitatio Sepulchri:

Otrosi, en las iglesias non se deven fazer juegos, sinon si sean juegos de las fiestas, asi commo de las Marias e del monumento, pero an de catar los clerigos que por tales juegos non trayan el divinal ofiçio ${ }^{46}$.

Aunque escrito en el siglo XIV, esta fuente pone de manifiesto la existencia de una liturgia teatral de la Pasión arraigada en la zona en siglos previos, a la cual la talla y capilla de San Justo no fueron ajenas ${ }^{47}$. J. F. Massip ha estudiado la importancia del marco arquitectónico de ciertos edificios localizados en el Este peninsular, en función de los textos conservados referentes al teatro litúrgico representado entre sus muros ${ }^{48}$. Como en estos casos, la liturgia teatral llevada a cabo en San Justo se concentraría en la zona oriental de la iglesia, donde el Cristo de los Gascones debía ser izado en la Cruz, descendido y 'sepultado' en la capilla del Santo Sepulcro hasta el Domingo de Resurrección, momento en que se

Teológico y popular de los siglos XII al XVI, en "Actas del Tercer Encuentro para el Estudio Cofradiero: en torno al Santo Sepulcro. Zamora 10/13 noviembre, 1993", Zamora, 1995, pp. 91-109) niega, con referencia a este documento, la existencia de procesiones castellano-leonesas hasta el siglo XVI.

${ }^{46}$ Synodicon Hispanum, edic. dirigida por A. García y García, vol. VI, Ávila y Segovia, Madrid, 1993, pág. 351. El sínodo de Ávila de 1481 también incidió en la prohibición de los escarnios que se producían en la catedral e iglesias del obispado durante las representaciones de Navidad, en San Esteban, San Juan Evangelista y en la festividad de los Inocentes. Sobre el caso abulense, vid., A. GómEZ MORENO, Teatro religioso medieval en Ávila, "El Crótalon. Anuario de Filología Española”, 1 (1984), pp. 769-775 y Synodicon Hispanum, cit., pp. 130131.

${ }^{47}$ Perteneciente al siglo XVI, la Biblioteca Capitular de la Catedral de Segovia conserva una copia de los usos litúrgicos de las iglesias de Guadix y Granada, realizada para la Iglesia segoviana. Aunque recoge el Quem queritis y la Visitatio, se trata de una ceremonia mucho más espectacular y con mayor aparato escénico [E. CASTRO CARIDAD (ed.), Teatro medieval. 1 El drama, cit., pp. 183-185].

${ }^{48}$ Se trata de las catedrales de Valencia y Mallorca, las iglesias de Santa María de Elche (Alicante), Santa María de Cervera (Lleida) y el templo monástico de Santa María de l'Estany (Barcelona) [J.F. MASSIP, Notes sobre l'evolució de l'espai escènic medieval als Països Catalans, "Acta Historica et Archaeologica Mediaevalia”, 5-6 (1984-1985), pp. 129-159]. En la Seo de Girona se conservan importantes testimonios de la actividad litúrgico-teatral a realizar en el espacio arquitectónico de la catedral e iglesias de sus inmediaciones durante los ciclos de Navidad y Pascua [Vid. LI. LUCERO COMAS, Litúrgia i paralitúrgia del dia de Nadal a la Seu de Girona segons la consueta de 1360, “Annals de l'Institut d'Estudis Gironins", XXXV (1995), pp. 159-181 y T. ROMAGUERA I GüELL, Drames litúrgics del cicle de Pasqua a la ciutat de Girona, "Annals de l'Institut d'Estudis Gironins", XXXV (1995), pp. 183-199] 
representaría la Visitatio Sepulchri: Tras la compra de los ungüentos para ungir el cuerpo de Jesús, las tres Marías se dirigen al sepulcro, donde encuentran al ángel que les pregunta a quién buscaban ${ }^{49}$, produciéndose entonces un cruce de frases que culminan en el testimonio de la Resurrección $^{50}$. La cruz, hasta el momento depositada en el sepulcro, es llevada de nuevo al altar ${ }^{51}$.

La aparición de capillas con advocación al Santo Sepulcro se ha constatado desde la Alta Edad Media, siendo especialmente profusas en ámbitos monásticos europeos entre los siglos IX y $\mathrm{X}^{52}$. La mayor parte de éstas surgieron como imitaciones arquitectónicas de la rotonda de la Anástasis de Jerusalén ${ }^{53}$. Por contra, existieron otras capillas y altares con la misma dedicación que no imitaban el edificio constantiniano, sino que se integraban dentro de la topografía eclesial ${ }^{54}$. G. Bresc-Bautier ha señalado

${ }^{49}$ "Quem queritis in sepulchro hoc, cristicole?"

${ }^{50}$ Conservamos textos litúrgicos de la Visita al sepulcro datados entre los siglos XI y XV en Vic (Barcelona), Girona, Urgell (Lleida), Santo Domingo de Silos (Burgos), Santiago de Compostela, Gandía, Granada, Guadix, Zaragoza y Segovia [Vid. la edición, transcripción y traducción de estos textos en E. CASTRO CARIDAD (ed.), Teatro medieval. 1 El drama, cit., pp. 111-188].

${ }^{51}$ Cf. B.D. BERGER, Le Drame liturguique de Pâques, Paris, 1976.

${ }^{52} \mathrm{Se}$ ha subrayado el papel de la llegada de los usos litúrgicos practicados en Jerusalén a través del tamiz de la liturgia romana, en la celebración de ceremonias vinculadas al Santo Sepulcro o la Santa Cruz en el resto de Europa desde época carolingia (C. HEITZ, Metz et son groupe épiscopal à l'époque pré-carolingienne et carolingienne, "Églises de Metz dans le Haut Moyen-Âge. Centre de Recherches sur l'Antiquité Tardive et le Haut Moyen-Âge”, IV, 1982 pp. 5-13, especialmente p. 13). Dichos modos ceremoniales dejaron su impronta arquitectónica en la creación de espacios bajo la advocación del Sepulcro de Cristo.

${ }^{53}$ Son capillas de planta central como en los casos de Fulda, Constance, Saint-Maurice de Vienne o Reichenau-Mittelzell. Vid. C. HeITz, Eléments carolingiens dans l'architecture méditerranéenne, "Les Cahiers de Saint-Michel de Cuxa", 12 (1981), pp.; IDEM., Art et liturgie, cit.; N.K. RASMUSSEN y E. PALAZZO, Messes privées, livre liturgique et arquitecture. A propos du Ms. Paris, Arsenal 610 et de l'église abbatiale de Reichenau-Mittelzell, "Revue des Sciences Philosophiques et Théologiques", 72 (1988), pp. 77-87. También, G. BRESCBAUTIER, Les imitations du Saint-Sepulcre de Jérusalem (IX" $\mathrm{XV}^{\prime \prime}$ siècles). Archéologie d'une devotion, "Revue d'Histoire de la Spiritualité", 50 (1974), pp. 319-342. Sobre el caso catalán vid. J. VIGUÉ ET AL., Les esglésies romàniques catalanes de planta circular $i$ triangular, Barcelona, 1975 y F. ESPAÑOL BERTRÁN, Massifs occidentaux dans l'architecture romane catalane, "Les Cahiers de Saint-Michel de Cuxa", XXVII (1996), pp. 57-77, especialmente, 65-67. En el complejo arquitectónico de Santo Stefano de Bolonia (Italia) se reinterpretaron otros espacios del conjunto hierosolimitano además de la rotonda de la Anástasis [R.G. OSTERHOUT, The Church of Santo Stefano: A 'Jerusalem' in Bologna, "Gesta”, XX/2 (1981), pp. 311-321]

${ }^{54}$ Para el caso carolingio, vid. C. HEITZ, Recherches sur les rapports entre architecture et liturgie à l'époque carolingienne, Paris, 1963, pp. 91-121 e IDEM., Architecture et liturgie en France de l'époque carolingienne à l'an mil, "Hortus Artium Medieualium", 1 (1995), pp.57- 
las características funerarias, relicarias y litúrgicas de las citadas imitaciones del Sepulcro, que tuvieron una mayor difusión en los siglos XII y XIII, como edificios vinculados a las órdenes militares de Tierra Santa ${ }^{55}$.

La capilla de San Justo no es un edificio relicario reproduciendo el esquema edificatorio del Santo Sepulcro de Jerusalén, modelo que sí fue seguido para la citada iglesia segoviana de la Vera Cruz. El edículo superior de la Vera Cruz albergó una imagen de Cristo yacente hoy conservado en la localidad de Zamarramala que enfatiza aún más el significado del edificio como réplica del Santo Sepulcro de Jerusalén ${ }^{56}$. Así pues, la capilla que tratamos tuvo un uso cultual en el que la asimilación del orden arquitectónico del edificio hierosolimitano fue innecesaria. Debemos destacar que no se trató de un caso único. Existieron paralelos de capillas al Santo Sepulcro ubicadas en torres, como es el caso de la conservada torre románica de la catedral de Vic y en la torre del brazo norte del transepto de la iglesia de Sant Pere de Galligans (Girona) $)^{57}$. Por otra parte, la advocación del ejemplo segoviano tampoco fue una materia singular en los reinos de Castilla y León ${ }^{58}$. En cuanto al Cristo de los Gascones, existen otras imágenes articuladas de Cristo, entre las que cabe destacar las zamoranas de la Trinidad de Toro y de San Lorenzo de Villalcampo ${ }^{59}$. En cuanto a imagenes medievales del yacente, simplemente citar las de Castiltierra (Segovia),

73. Sobre las capillas en los macizos occidentales de las catedrales románicas de Barcelona, Girona y Vic, vid. F. ESPAÑol BERTRÁN, Massifs occidentaux, cit., pp. 67-77. Acerca del mundo anglonormando, vid., A.W. KLUKAS, Altaria superioria: The Function and Significance of the Tribune-chapel in Anglo-Norman Romanesque. A problem in the Relationship of Liturgical Requirements and Architectural Form, Ph. D. Diss., 2 vols., University of Pittsburgh, 1978, vol. 1, pp. 77-95.

${ }^{55}$ G. Bresc-BAutieR, Les imitations du Saint-Sepulcre, cit., pp. 328-330.

${ }^{56}$ Cf. J.M. Santamaría López, La Vera Cruz, Segovia, 1979 y I.G. Bango Torviso, Arquitectura y escultura, en "Historia del Arte de Castilla y León", t. II, Valladolid, 1995, pp. 9-212, pág. 172.

${ }^{57}$ F. ESPAÑol BerTRÁN, Massifs occidentaux, cit., p. 71.

${ }^{58}$ En la ciudad de León conservamos la memoria de una iglesia del Santo Sepulcro, también situada en el burgo de los francos, mandada construir por la reina Urraca y en cuyo cementerio se daba enterramiento a los peregrinos a Santiago. La advocación al Santo Sepulcro aparece también, entre otros lugares, en Santiago de Compostela, Zamora y Toro (Zamora).

${ }^{59} \mathrm{Vid}$. las fichas respectivas en el catálogo Santo Entierro en Zamora. Exposición organizada con motivo del 400 aniversario de la fundación de la Real Cofradía del Santo Entierro en Zamora, Zamora, 1994, pp. 52-55. 
las de San Lázaro, Santa Clara y el Santo Sepulcro en Zamora ${ }^{60}$, el grupo de la Virgen y San Juan ante Cristo muerto de León (Museo CatedralicioDiocesano) y, en la misma ciudad de Segovia, la aludida imagen originaria de la iglesia de la Vera Cruz, hoy en la localidad de Zamarramala. Aunque todas ellas están fechadas en el siglo XIV, vuelven a incidir en el mismo culto y su expresión plástica.

La importancia de la capilla del Santo Sepulcro en San Justo de Segovia radica en ser el precoz testimonio material de un culto pascual vinculado a actos litúrgicos, representando el drama de la Pasión de Cristo. El Cristo de los Gascones es el ejemplo de un tipo de representación escultórica, que hallará un profundo eco en siglos posteriores, presentando además la peculiaridad de su utilización como parte integrante de la mencionada liturgia.

\section{RÉSUMÉ}

Hors des murs de la ville de Segovie, au lieu-dit El Cerrillo, se trouve l'église de San Justo. À l'intérieur, il y a un cycle de peintures murales romanes, une sculpture articulée du Christ gisant connue sous le nom de Cristo de los Gascones, une chapelle au-dessous de la tour et un tympan sculpté sur la porte d'accès à la chapelle. Tous ces éléments sont attribués aux XII ${ }^{\mathrm{e}}$ et XIII ${ }^{\mathrm{e}}$ siècle. Leur étude montre que cette chapelle était sans doute dédiée au culte du Saint-Sépulcre en Castille.

\section{SUMMARY}

The parish church of San Justo in Segovia is located outside the city, in the suburb of El Cerrillo. Inside the church there are Romanesque wall paintings, an articulated reclining statue of Christ known as el Cristo de los Gascones, a chapel in the first storey of the tower and, finally, a sculptured tympanum in the door that gives way to the chapel. All of them can be dated to the 12 th and 13th-centuries. The analysis of these elements gives us the key to the functionality of the tower chapel, as one of the areas dedicated to the devotion of the Holy Sepulchre in Castile.

\footnotetext{
${ }^{60} \mathrm{D}$. DE LAS HERAS HERNÁNDEZ, Catálogo artístico-monumental y arqueológico de la diócesis de Zamora, Zamora, 1973, pp. 186, 215 y 266; Santo Entierro en Zamora, cit., pp. 62-67.
} 